DOI: $10.14451 / 2.156 .60$

\title{
ЭКОНОМИКА И ГРАЖДАНСКОЕ ПРАВО: ПРОБЛЕМЫ СООТНОШЕНИЯ В СФЕРЕ УСЛУГ
}

\section{(c) 2021 Ялунина Екатерина Николаевна}

доктор экономических наук, профессор кафедры конкурентного права и антимонопольного регулирования Уральский государственный экономический университет, Россия, Екатеринбург

\section{(C) 2021 Мансуров Гафур Закирович}

доктор юридических наук, доцент, заведующий кафедрой гражданского права Уральский государственный экономический университет, Россия, Екатеринбург

В статье проведено исследование как развитие реального сектора экономики подвержено влиянию сформировавшегося практического применения действующего законодательства. Понятие «реальный сектор экономики» в законодательстве отсутствует, но в ряде нормативно-правовых актов существует изложение мер государственной поддержки рыночных субъектов ряда отраслей экономики, в частности сельского хозяйства, предприятий пищевой и перерабатывающей промышленности, строительства, транспорта, сферы услуг. Государство отводит приоритетную роль праву с целью определения «правил игры», которые несомненно оказывают влияние на объекты экономической системы, в частности на конечные показатели рыночных субъектов таких как рентабельность производства, продаж, затрат и уровень платежеспособности населения. Исследование в рамках заявленной темы актуально, оно направлено на определение степени воздействия права на экономику.

Ключевые слова: экономика, право, реальный сектор экономики, предприятия пищевой и перерабатывающей промышленности, уровень влияние.

Экономический рост национальной экономики напрямую зависит от развития сферы услуг, так как в условиях ее трансформации, роль сферы услуг связана с влиянием таких факторов как, информационные технологии, уровень знаний, сформировавшийся человеческий капитал, процессы глобализации. Рассматривая сферу услуг, в частности оптовую и розничную торговлю, бытовые, социальные, страховые, финансовые услуги нами определены критерии оценки как универсальные, так и имеющие специфику. Запросы потребителей формируют портфель заказов для производства новых товаров и как следствие их продвижение на рынок. Проводя исследование развития сферы услуг зарубежных стран, констатируем, что $76 \%$ в ВВП занимает сфера услуг и причисляется к крупнейшему сектору экономики. Приоритетными направлениями развития сферы услуг являются лизинговые операции, аудиторские, инженерностроительные услуги, по найму работников. За последние годы сфера услуг активно развивается, доля в ВВП в 2017 году составила 69\%. Особое место в развитии сферы услуг занимает предпринимательство, которое формирует обособленную среду с определенным уровнем культу- ры, знаний, наличием ресурсов. Наличие разных организационно-правовых форм и сложившихся систем управления позволяет предпринимательству в сфере услуг достигать нормируемых показателей, несмотря на влияние внешних факторов на макро и мезоуровнях. Для дальнейшего развития предпринимательства необходимо совершенствовать профессиональный уровень работников, отсутствие инновационного маркетинга, новые рынки сбыта. Нужно изучать опыт развитых стран и выстраивать с ними хозяйственные связи. Часть существующих организаций сферы услуг не занимаются изучением конъюнктуры рынка услуг. Не достаточно уделяют внимания на повышение качества реализуемых услуг, а современный потребитель имеет опыт сравнения с аналогичными организациями других стран. Происходит диссонанс на рынке, установленные цены на услуги организациями не соответствует ожиданиям потребителя, в частности низкий уровень качества по завышенным ценам. Следующей проблемой для российской сферы услуг остается низкий уровень научно-технической обеспеченности рыночных субъектов, а также нормативно-правовое регулирование. 
Таблиц̧а 1. Характеристика проблемы соотношения экономики и гражданского права

\begin{tabular}{|c|c|}
\hline П.Е. Казанский & $\begin{array}{l}\text { «юридические явления, явления, изучаемые наукой права, не представляют собой } \\
\text { чего-либо обособленного, оторванного от остальных отношений общественной жизни. } \\
\text { Поэтому, чтобы изучить, понять и объяснить их, недостаточно рассматривать их самих } \\
\text { по себе и самих в себе» }[8, \text { С.1] }\end{array}$ \\
\hline Я.А. Канторович & $\begin{array}{l}\text { «отношения человека по имуществу отличаются в особенности свойством права; они } \\
\text { составляют главное содержание права гражданского: к ним в особенности прилагается } \\
\text { понятие о моем и твоем» }[8, \mathrm{C.80}]\end{array}$ \\
\hline К.П. Победоносцев & $\begin{array}{l}\text { «тесная связь предметов гражданского, особливо вотчинного, права с экономией, де- } \\
\text { лает невозможным, в наше время, изучение первого, без изучения последней» [18, Т.1. } \\
\text { С.744] }\end{array}$ \\
\hline Ф. Эндеманн & $\begin{array}{l}\text { «напрасен труд юриста, если нормы, которые он устанавливает или применяет, проти- } \\
\text { воречат научным данным политической экономии» }[9, \text { С.6] }\end{array}$ \\
\hline В.И. Авдийский & $\begin{array}{l}\text { «основной причиной указанных проявлений является прежде всего то, что все малоэф- } \\
\text { фективные нормы разрабатывались без учета экономической составляющей процессов, } \\
\text { которые должны были регулировать соответствующие нормы закона» }[1, \text { С.29] }\end{array}$ \\
\hline Ю.С. Гамбарова & $\begin{array}{l}\text { «указывало на зависимость права от экономических отношений и настаивало на изуче- } \\
\text { ние правовых явлений в связи с экономическими» }\end{array}$ \\
\hline К. Маркс & $\begin{array}{l}\text { «мои исследования привели меня к тому результату, что правовые отношения, также } \\
\text { точно, как и формы государства, не могут быть поняты ни из самих себя, ни из так } \\
\text { называемого общего развития человеческого духа ... наоборот, они коренятся в мате- } \\
\text { риальных жизненных отношениях ... и что анатомию гражданского общества следует } \\
\text { искать в политической экономии» [15, Т.4. С.112] }\end{array}$ \\
\hline Ф. Энгельс & $\begin{array}{l}\text { «главный упор мы делали, и должны были делать, сначала на выведение политических } \\
\text { и правовых и прочих идеологических представлений и обусловленных ими действий из } \\
\text { экономических фактов, лежащих в их основе» [15, T.21. С.311] }\end{array}$ \\
\hline В.П. Шкредов & $\begin{array}{l}\text { «для того, чтобы законодательство, регулирующее экономическую жизнь, стало высо- } \\
\text { коэффективным, законы государства не должны содержать в себе регламентации всего } \\
\text { того, что по своему объективному характеру не поддается правовому регулированию» } \\
{[29, \text { С.257]. }}\end{array}$ \\
\hline Л.С. Явич & $\begin{array}{l}\text { «правоотношения, которые регулируют фактически существующий вид общественных } \\
\text { отношений, и такие правоотношения, которые сами по себе (но опираясь на фактиче- } \\
\text { ские обстоятельства) образуют особый вид отношений, без них вообще не существую- } \\
\text { щий» [30, С.24] }\end{array}$ \\
\hline О.Т. Богомолова & $\begin{array}{l}\text { «право в рыночной экономике нельзя рассматривать лишь как юридическое оформле- } \\
\text { ние объективно сложившихся экономических отношений» [5, С.28-29]. }\end{array}$ \\
\hline С.С. Алексеев & $\begin{array}{l}\text { «следует признать упрощенным взгляд, в соответствии с которым позитивное право, } \\
\text { происходящие в нем изменения, модификации напрямую связывают с экономикой, } \\
\text { идеологией и т.д. Процесс тут более сложен. Соответствующие объективно обусловлен- } \\
\text { ные требования, продиктованные жизнью - экономикой, идеологией и др., во-первых, } \\
\text { идут через всю инфраструктуру социального регулирования данного общества и через } \\
\text { его сложный механизм «выходят» на право, а во-вторых, преломляются в этой инфра- } \\
\text { структуре через ее наиболее глубокий слой - непосредственно-социальные права» [2, } \\
\text { С.63] }\end{array}$ \\
\hline Г.Д. Берман & $\begin{array}{l}\text { «более уместно и полезно говорить о взаимодействии политики, экономики, права, } \\
\text { религии, искусства, идей без расчленения этих нераздельно связанных сторон обще- } \\
\text { ственной жизни на «причины» и «следствия» [4, С.521] }\end{array}$ \\
\hline С.И. Аскназий & $\begin{array}{l}\text { «экономические условия не являются единственной активной причиной возникнове- } \\
\text { ния и дальнейшего движения ... правовых институтов; экономические отношения и } \\
\text { здесь нередко лишь в конечном счете являются решающими, и на них весьма сильно } \\
\text { влияют остальные политические и идеологические условия» [3, С.145]. }\end{array}$ \\
\hline Д.С. Львов & «крупномасштабную примитивизацию экономической мысли» [14, С.25]. \\
\hline К.Р. Поппера & $\begin{array}{l}\text { «научное мышление, в особенности, мышление о политических и социальных пробле- } \\
\text { мах, происходит не в вакууме, а в социально обусловленной атмосфере», «социальная } \\
\text { среда мыслителя определяет целую систему убеждений и теорий, которые представля- } \\
\text { ются ему, безусловно, истинными или самоочевидными» [20, Т.2.C.246]. }\end{array}$ \\
\hline Дж. Сорос & $\begin{array}{l}\text { «Недостатки экономической науки вызваны не просто нашим несовершенным пони- } \\
\text { манием экономической теории или нехваткой адекватных статистических данных. } \\
\text { Экономические или общественные события, в отличие от событий, которые изучаются } \\
\text { физиками и химиками, включают мыслящих участников. И именно мыслящие участ-- } \\
\text { ники могут изменять правила экономической и общественной системы просто в силу } \\
\text { своих представлений об этих правилах» [25, С.32]. }\end{array}$ \\
\hline
\end{tabular}


Анализ проблемы соотношения экономики и гражданского права в сфере услуг позволит рыночным субъектам привнести в деятельность некие «правила игры», которые направлены на достижение рациональных показателей эффективности использования имеющегося совокупного потенциала, а также стать основой для повышения уровня их высокотехнологичного развития.

Проведя анализ проблемы соотношения экономики и гражданского права выделяем две проблемы, которые присуще развитию сферы услуг, в частности предпринимательству. Решение первой проблемы прослеживается в теории марксизма и часть авторов, обозначенных в исследовании, данный тезис подтверждают и с ними мы солидарны. Вторая проблема, которая подлежит дискуссии, демонстрирует общие принципы как в экономике, так и в юриспруденции. Но часть авторов указывает на ранее возникший этап возникновения права, как самостийный инструмент регулирования процессов в обществе, нежели чем экономика. И позднее описывают появление экономики как самостоятельную область исследования, в частности возникновение в Новом времени через полторы тысячи лет. Следующий этап взаимозависимости между экономикой и правом выявлен в фазе активно расцвета политэкономии. Причем, западноевропейские специалисты рассматривают данные вопросы в контексте доминирования экономических процессов над юридическими, что позволило укрепить политэкономию как самостоятельную научную область знаний и определить тесные связи с естествознанием, что подчеркивало ее изменение в динамике, следовательно, появилась возможность изучать ее развитие. Право, как науку рассматриваем с точностью наоборот, она отражает реальность сегодняшнего дня, т.е. более статична и ей не позволительны вольности, а ее позиционирование ограничено сводом правил, норм. Как доказательство течение нормативизма существовало и в те времена и актуально и по сей день. Нормативизм в работах рассматривается как обособленная функция, наделенная государственными органами управления, утверждающая правовые нормы. Марксизм, ленинизм, процветающий в эпоху административно-командной системы управления государством, отражало веяния экономизма, в частности «Манифест Коммунистической партии» это констатирует. Сущность ма- нифеста заключается, что воля существующего класса возведена в закон, т.е. наблюдается тесная связь права и обеспечение материальными благами общества. В данной научной категории невидимая связь усиливается и приближает его к экономической основе. Естественно-правовая доктрина демонстрирует развитие исследуемых научных дефиниций, усиливает позиции права. Сгруппированная политическая воля диктует сценарий развития государства посредством правового закона. Хотя и прослеживается диаметральная точка зрения, выраженная в рассуждениях и определении влияния волевых поступков.

Таким образом, существующая практика директивной экономики констатировала, что реализация социально-экономического сценария развития национальной экономики должна осуществляться в рамках правового регулирования, соблюдая принципы права собственности, конкуренции, гибкой фискальной политики. Под сферой услуг мы понимаем, наличие видов деятельности, сконцентрированных посредством производства и реализацию услуг потребителям, которые четко формулируют запросы через потребительские ожидания. Считаем необходимым подчеркнуть влияние права на развитие сферы услуг как сектора национальной экономики, который подвержен правовому регулированию со стороны органов государственной власти. Правовое регулирование в данном секторе наделено специфическими условиями, которые проявляются в виде многообразия интересов заказчика услуг, причем как коммерческого, так и некоммерческого характера.

Очевидно, что позиция сторонников экономического детерминизма была бы обоснованной только в случае, когда законодатель, при разработке нормативных актов, руководствовался бы только экономическими соображениями и эти соображения были бы достоверными.

Разработка стратегии развития отраслей сферы услуг сопровождается правовом обеспечением и является базисом для ее реализации. Проблемой в настоящее время является то, что существующая законодательная база регионами трактуется и исполняется не всегда в точной мере ее изложения. Основными документами, регламентирующих нормативно-правовое регулирование в сфере услуг являются Гражданский кодекс, Налоговый кодекс, Закон о конкуренции, защите прав потребителей, лицензировании и 
др. Государственное управление в сфере услуг также многоуровневое, например, организация выездного комплексного бытового обслуживания в сельской местности регламентирована на муниципальном уровне. Помимо государственного многоуровневого управления в сфере услуг, мы отмечаем его разнонаправленность, в частности социально-экономическое, культурнодосуговое, научное и ряд других. Современные авторы трактуют, что система государственного управления должны быть выстроена вертикально и применять комплексный подход. Сущность которого заключается в реализации конкурентоспособной услуги, которая соответствует ожиданием запросов потребителей. Реализация целевой программы «Развитие внутреннего и въездного туризма в Российской
Федерации (2011-2018 г.г.)» является примером комплексного подхода в обеспечении конкурентоспособной услуги на территории Российской Федерации. Опираясь на вышеизложенное, мы подчеркиваем, что право и экономика взаимозависимы друг от друга и подвержены влиянию других факторов, таких как влияние политической целесообразности. Также можно резюмировать, что принятые ряд нормативных актов не отражают ситуацию в реальном секторе экономики по причине непонимания, либо недостаточно проведенного глубокого исследования, в том или ином вопросе и требует принятия ряда поправок, либо намеренного принятия решения не в пользу определенных целевых групп, а преследуя в первую очередь интересов государства.

\section{Библиографический список}

1. Экономический анализ права: сравнительно-правовое исследование [Текст] / В. И. Авдийский // Международное публичное и частное право. - 2012. - № 3.- с. 26-29.;

2. Алексеев С. С. Теория права.-М.: Изд-во Бек, 1993.-223 с.;

3. Аскназий С.И. Основные вопросы теории социалистического гражданского права [Текст] / С. И. Аскназий; науч. ред. В.С.Ем.- М.: Статут, 2008. 856 с.;

4. Берман Г.Дж. Западная традиция права: эпоха формирования / Пер. с англ.-2-еизд.- М.: Изд-воМгУ: Издательская группа ИНФРА- М - НОРМА,1998. - 624 с.;

5. Богомолов О.Т. Реформы в зеркале международных сравнений [Текст] / О. Т. Богомолов.- Москва: Экономика, 1998.- 159 с.;

6. Бродский М.Н. Законодательная база экономического развития [Текст] / М.Н.Бродский.- СПб.: Европейский дом, 2002.- 592 с. - (Право и экономика);

7. Гамбаров Ю. С. Гражданское право. Общая часть / Ю. С. Гамбаров; Под ред. В.А. Томсинова.- М.: Зерцало, 2003 (ППП Тип. Наука). - 796 с.;

8. П. Казанский. Введение в курс международного права. Одесса, 1901 [Текст]. А.Пиленко. // Право.-1901.[№ 1-52].- С. 512-517;

9. Канторович Я.А. Основные идеи гражданского права/ С предисл. А. Малицкого.-Харьков: Юрид. изд-во НКЮ УССР, 1928. - 310 с. // Революция права.- М.: Изд-во Ком. Акад., 1928, № 2.- С. 163-166;

10. Карсон Роберт Б. Что знают экономисты: основы экономической политики на 1990-е годы и в перспективе / Роберт Б. Карсон; отв. ред. В.Р.Евстигнеев.- Москва: Квадрат, 1993. - 308 с.;

11. Кленнер Г. От права природы к природе права. Перевод с немецкого / Кленнер Г.; Под ред.: Куркин Б.А.; Пер.: Бекназар-Юзбашев Т.Б.; Вступ. ст.: Мамут Л. С.- М.: Прогресс, 1988. - 320 с.;

12. Семеко Г. В. 95.01.002. Кульман А. Экономические механизмы / пер. С ФР. Островской Е. П.; общ. Ред. Хрусталевой Н.И.-М.: прогресс, 1993.-189 с.;

13. Лившии Р. З. Теория права. Учебник / Лившиц Р.3.- М.: БЕК, 1994.-224 с.

14. Львов, Д. С. Развитие экономики России и задачи экономической науки.- М.: Экономика, 1999. - 80с.;

15. К. Маркс, Ф. Энгельс. Сочинения, тома 1-39. Издание второе М.: Издательство политической литературы, 1955-1974 г.г.;

16. Морандьер Ж. Л. Гражданское право Франции. Перевод с французского. Т. 2 / Жюллио де ла Морандьер Л.; Пер. и вступ. ст.: Флейшиц Е.А.- М.: Иностр. лит., 1960.- 728 с.;

17. Ожегов С.И., Шведова Н. Ю. Толковый словарь русского языка. М., 1992.;

18. Победоносцев К.П.Курс гражданского права: Вотчинные права. Ч. 1 / Победоносцев К.П.; Науч. ред.: Ем В.С.-М.: Статут, 2002.- 800 с.;

19. Общая теория права: Учебник / Поляков А.В., Тимошина Е.В., - 2-е изд.-СПб: СПбГУ, 2015. - 472 с.; 
20. Поппер Карл Раймунд П 57 Открытое общество и его враги. Т. 1: Чары Платона. Пер. с англ. под ред. В. Н. Садовского.-М.: Феникс, Международный фонд «Культурная инициатива», 1992.-448 с.;

21. Правовая система социализма: Понятие, структура, социальные связи. Кн. 1 / Васильев А. М., Гаврилов О.А., Казимирчук В.П., Кудрявцев В.Н., и др.; Редкол.: Васильев А.М. (Отв. ред.), Казимирчук В.П., Кудрявцев В.Н.- М.: Юрид. лит., 1986.- 368 с.;

22. Самуэльсон П.А. Экономика: [Учеб. пособие для студентов, обучающихся по экон. направлениям и специальностям] / Пол А.Самуэльсон, Вильям Д.Нордхаус; Пер. с англ. под ред. Тарасевича Л.С., Леусского А.И.-М.: Бином: Изд. торговый дом «КноРус», 1997. - 799 с.;

23. Семякин М. Н. Экономика и право: проблемы теории, методологии и практики / Под общ. ред. А. И. Татаркина. Екатеринбург, 2006. С. 41-65.;

24. Сорос, Джордж. Открытое общество. Реформируя глобальный капитализм / Джордж Сорос; [Пер. с англ.].М.: Некоммер. фонд поддержки культуры, образования и новых информ. технологий, 2001. - 455, [3] с.;

25. Сорос Дж. Кризис мирового капитализма: Открытое об-во в опасности / Пер. с англ. Умрихиной С. К., Штернгарца М.3.- М.: ИНФРА-М, 1999.-261 с.;

26. Сырых В. М. Логические основания общей теории права: в 2 Т. Т. 1. Элементный состав. М.: Юстицинформ, 2000. 528 c;

27. Теория государства и права /под ред. М.Н. Марченко. М., 2011.;

28. Шершеневич Г. Ф. Наука гражданского права в России / Шершеневич Г.Ф.; Науч. ред.: Ем В. С. - М.: Статут, 2003. - 250 c.;

29. Шкредов В. П. Экономика и право. Опыт экономико-юридического исследования общественного производства / Шкредов В. П.; Ред.: Басырова З.А..-2-е изд., перераб. и доп.- М.: Экономика, 1990.- 270 с.;

30. Явич Л. С. Общая теория права / Явич Л. С.; Под ред.: Королев А.И.-Л.: Изд-во Ленингр. ун-та, 1976. - 285 с.;

31. Яковлев А. М. Социология экономической преступности / Яковлев А. М.; Отв. ред.: Кудрявцев В.Н.- М.: Наука, 1988.-256 с. 